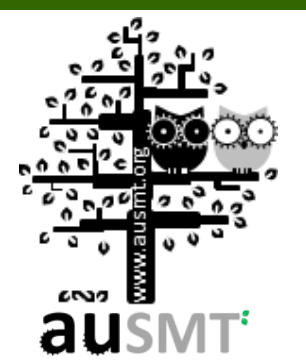

\title{
Exploring the Innovative Value of the RFID Industry
}

\author{
Pei-Shu Fan ${ }^{1}$, Cheng-Chin Tsao ${ }^{2}$, and Yi-Ching Liaw ${ }^{3, *}$ \\ ${ }^{1}$ Department of Industrial Engineering and Management, China University of Science and Technology, Taiwan \\ ${ }^{2}$ The Graduate School of Business \& Management, China University of Science and Technology, Taiwan \\ ${ }^{3}$ Department of Business Management, Ming Chi University of Technology, Taiwan \\ (Received 15 March 2013; Accepted 11 June 2013; Published on line 1 September 2013) \\ *Corresponding author: ycliaw@mail.mcut.edu.tw \\ DOI: 10.5875 /ausmt.v3i3.201
}

\begin{abstract}
Nearly every industry is increasingly reliant on patent protections, and the future of entire industries and even countries can be analyzed and predicted based on patent development. Countries are responding to the rapid development of RFID applications by aggressively protecting pursuing and protecting RFID innovations. This study examines a number of patent indicators to predict and explain future technological developments in the RFID industry, thus providing insights for economic planning at the national scale. Patent indicators such as the number of patent applications and Patent Cooperation Treaties (PCTs) are used to analyze technological development trends in the context of overall development for Europe, Asia, and America, and to identify valuable technological development directions. Distributions of RFID patents are then used with the Revealed Patent Advantage (RPA) to conduct cluster analysis of K-means, thus providing insight into relative regional technological advantages in RFID development. Finally we discuss the future creative value of the Taiwanese market and its development direction.
\end{abstract}

Keywords: RFID; patent indexes; patent analysis; RPA indexes; cluster analysis

\section{Introduction}

Radio Frequency Identification (RFID) is a non-contact automatic identification technology, using radio waves to identify hardware tags installed on the target items. This technology can be used for wireless data identification and information retrieval [1]. Unrestricted by spatial limitations, RFID offers fast data exchange for item tracking, and for the acquisition, categorization, and statistical analysis of relevant data [2].

In recent years, many countries have devoted significant resources to the development of domestic RFID industries. Tokyo's Narita Airport has a program called Simplifying Passenger Travel (SPT) where RFID tags attached to baggage allow travelers to track their luggage online. NEC (Nippon Electric Company, Limited) Corp. has established ventures in China to use RFID technology to monitor cold chain logistics for food processing and distribution.

The application of RFID technology to an increasingly broad range of fields is spurring demand for the development of related technologies. Countries around the world have increased investments in RFID technology, hoping to gain technological breakthroughs which they intend to secure through patents. This study applies patent analysis methods and tools to examine the development of RFID technology around the world to predict possible future technological developments.

[3] notes that a patent's value is determined by the commercial advantage it brings the patent holder. [4] suggest patents potentially provide competitive advantage, while facilitating monitoring technology 
development within particular industries and securing the patent holder's interests against infringement. Therefore, countries and industries will seek to protect improved and innovative technologies through patents.

[5] applied patent maps in their analysis of the overall development directions for storage technologies, with results indicating the superb performance of innovative bar code scanning technologies. [6] suggested that analyzing patents for valuable information is time and labor intensive. A series of text mining techniques was used to conduct patent analysis and propose suitable applications of patent-related research methods for analysis and mapping, and these methods facilitate patent categorization, knowledge sharing, and the review of current technologies. [7] analyzed patents using patent maps and the classification of patent documents. [8] used patent information from the US Patent and Trademark Office (USPTO), the European Patent Office (EPO), and Taiwan Patent Search System to analyze production technology life cycles and patent grants for wind power technology from the US, Europe and Taiwan, thus contributing to the formulation of a national patent strategy. Her study indicated that patent analysis at the industry and national level can assist the formulation of effective patent strategies.

In "Intelligent Recommendation Methodology and System for Patent Search", [9] pointed out that the development of innovative technologies is essential to corporate competitiveness. Prior to submitting a patent application, inventors must search multiple databases to ensure that their innovation does not infringe on existing patents, and many efforts have been made to increase the efficiency of patent search $[10,11]$. Currently, such searches are still highly time-consuming and are one of the main tasks of R\&D staff. Their study uses an intelligent recommendation system to analyze patent search patterns with behavioral models defined to

\footnotetext{
Pei-Shu Fan received his Ph.D. degree from National Taipei University of technology, Taipei, Taiwan, in 2008. He is currently an Assistant Professor and Direct at the Chinese University of science and technology, Department of Industry Management, Military Defense Industry Cooperation Center, Taipei, Taiwan, (R.O.C.). His current research interests include science-technology strategy analysis, forecasting, and Industry analysis. He is the author and co-author of more than 10 papers published in international journals, including the journal of Expert System with Applications, the International Journal of Production Economics and Japanese Journal Applied Physical.

Cheng-Chin Tsao is now a graduate student in Business \& Management from China University of Science and Technology, Taiwan. Her research interests include an analysis of industry technology, an analysis of patent information, and data mining.

Yi-Ching Liaw received his MBA degree in management of technology from National Chiao Tung University, and a PhD degree in business administration from National Chung Hsing University, Taiwan. He is now an assistant professor at Department of Business Management, Ming Chi University of Technology, Taiwan. His research interests include technology innovation and strategy, performance evaluation, and strategic management.
}

determine user behavior and analyze the clustering results. The system also clusters users and their neighbors through a coordinated screening mechanism, summarizes the behaviors of neighbors and proposes appropriate patent search results to help users obtain relevant patents, thus saving time and expense.

[2] stressed the importance of patent analysis in evaluating technology changes. Their research analyzed every RFID-related patent in the USPTO database to create an overall innovation blueprint for the RFID technology field. [12] suggested that RFID patent analysis can not only help promote continuous innovation, but also promote understanding of innovation and technological knowledge worldwide. In their investigation of the fast-expanding Chinese RFID industry, [13] suggested that corporations monitor and evaluate market competition through patent analysis, and provided an overview of future likely directions for RFID technology development. Their research categorized different patent documents, grouping similar documents to facilitate the prediction and evaluation of future RFID development opportunities. Results indicated that the Chinese RFID market is either mature or saturated, and suggested that China needs to be more active in developing innovative technologies in the RFID industry.

In "Applying K-means Clustering and Technology Map in Asia Pacific-Semiconductors Industry Analysis," [14] analyzed and categorized semiconductor patents based on the country of origin and the IPC categorization standard. The number of patents for each country was then converted into its revealed patent advantage (RPA) in a specific field as an indication of each country's relative technical advantage and capability. Multi-Dimensional Scaling (MDS) was used to investigate each country's development position, and the clustering of adjacent points in space was examined using K-means analysis. Strategic groups were identified based on the similarity of these data points to determine the relative position of each country in the technical field and to suggest technical development strategies for Taiwan's semiconductor industry.

[15] identified three major types of patent index studies in Taiwan, namely the typical patent characteristics index, patent reference index and patent technology index. The typical characteristics index mainly describes the generic characteristics of a patent, while the patent reference index provides reference status information, and the patent technology index describes the performance of the technologies involved. If combined with other factors such as time and professional field, and expressed as quantity, frequency or composite indexes, these indexes can serve as a useful reference for companies, industrial sectors and countries. 
Our research uses the number of patent applications and the number of PCT applications to determine more valuable technological development directions for the RFID industry, and then uses RPA indexes and K-means clustering analysis to assess the relative advantages of various countries vis-à-vis their RFID technology and development directions. The study analyzes RFID-related patents to provide guidance for industrial and national decision makers in formulating patent portfolio strategies for the RFID industry.

\section{Research Methods}

\section{Overview of the study}

China, Germany, Japan, Korea, USA and Taiwan were selected as the objects of the analysis. The technical development and the position of RFID technologies in these six countries from 1990 to 2010 were investigated. It is hoped that this study of patent values will shed light on the value of innovation in the industry and directions of future development.

The RFID industry was investigated from the angle of patent analysis. Table 1 defines the analyzed technological classification in accordance with the Intellectual Property Office (version 8):

Table 1: Definition of technological classification.

\begin{tabular}{|c|c|}
\hline Classification & Definition \\
\hline $\mathrm{G} / 06 / \mathrm{F}$ & Digital electronic data processing \\
\hline $\mathrm{G} / 06 / \mathrm{K}$ & $\begin{array}{l}\text { Processing of data identification, data } \\
\text { representation and record carrier }\end{array}$ \\
\hline $\mathrm{G} / 06 / \mathrm{Q}$ & $\begin{array}{l}\text { Data processing systems or methods for } \\
\text { the purpose of administration, } \\
\text { management, commerce, business } \\
\text { running, supervision of prediction }\end{array}$ \\
\hline $\mathrm{G} / 07 / \mathrm{F}$ & $\begin{array}{l}\text { Coin-operated equipment or similar } \\
\text { equipment }\end{array}$ \\
\hline G/08/B & $\begin{array}{l}\text { Signaling or calling devices, command } \\
\text { issuing devices and alarming devices }\end{array}$ \\
\hline G/08/G & Traffic control systems \\
\hline $\mathrm{G} / 09 / \mathrm{F}$ & $\begin{array}{l}\text { Representation, advertisement, marking, } \\
\text { labeling or name tag and seal }\end{array}$ \\
\hline $\mathrm{H} / 04 / \mathrm{M}$ & $\begin{array}{l}\text { Telecommunication } \\
\text { technology/telephone communication/ } \\
\text { and auxiliary equipment }\end{array}$ \\
\hline H/05/B & $\begin{array}{l}\text { Electric heating and electric lighting not } \\
\text { included in other categories }\end{array}$ \\
\hline
\end{tabular}

RFID-related patents obtained from the National Applied Research Laboratories (NARL) were used as the basis for empirical analysis. Covering the past 150 years, this platform contains data over 80 million patents from 135 countries, making it the most complete and representative patent database in the world.

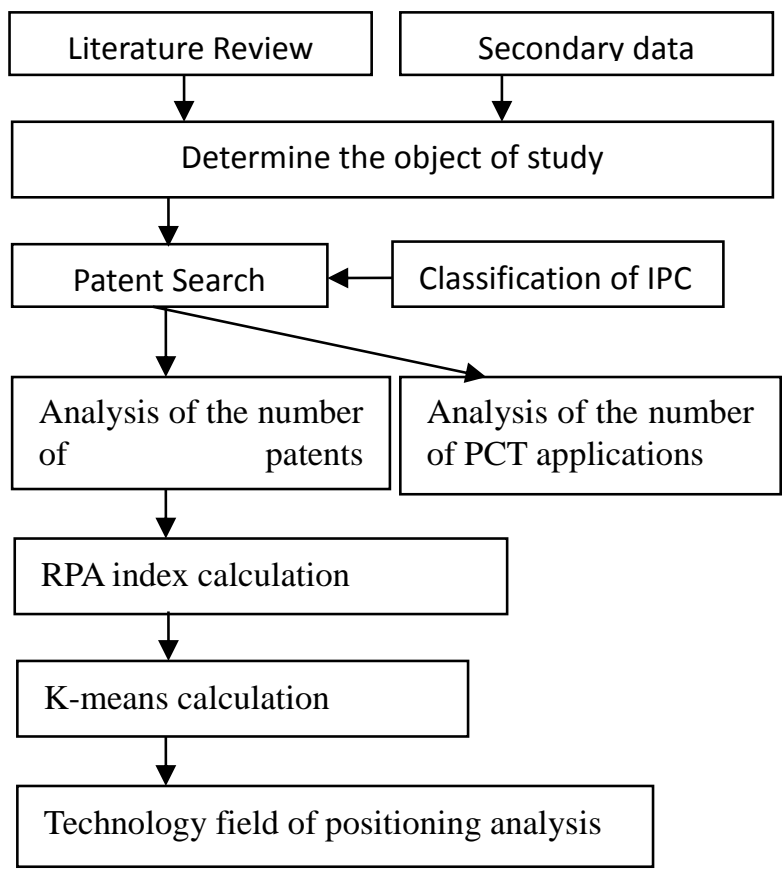

Figure 1. Study flow chart.

\section{The Research Process}

First, the patent indexes, number of applications and PCTs were used to assess RFID development in each country from the perspective of technological trends and technology types to identify trends in the RFID industry. RPA and K-means clustering analysis were then used to identify the position of RFID in each country, along with relative strengths/weaknesses in their RFID field and direction of future development. The study procedure is shown in Figure 1.

\section{Number of applications}

The number of patent applications provides a clear view of the evolution of a given technology and the general direction of the overall industry. A popular technology will show exponential growth in the number of applications. Applicants are likely to have significant resources related to the technology, or to consider the technology to be a core asset or resource. Thus the number of applications serves as a useful index for analysis. 
Number of PCTs

Patent Cooperation Treaties (PCTs) are global agreements under the auspices of the World Intellectual Property Organization (WIPO). PCTs facilitate international patent applications, allowing applicants to file for protection in multiple countries with a single application.

The PCT application process is generally divided into international and national phases. The international phase takes approximately 30 months to complete. Applications can be simultaneously filed in multiple countries, and applicants can use the application processing time to investigate market prospects, technological development, the economic value of the invention, and prior art through an international searching authority (ISA). The results of such an investigation will help patent applicants predict the market value of their invention. Therefore, this study uses the number of PCT applications as a means of identifying valuable directions for technology development within the RFID industry.

\section{Revealed Patent Advantage (RPA)}

Research and development strategies differ from country to country, and one must convert the original number of patent applications to a relative patent index to determine the respective capability and relative advantage of different countries in specific fields. Therefore, [16] defined RPA advantage as follows:

$$
R P A_{i j}=100 \tanh / n\left[\left(\frac{P_{i j}}{\sum_{i} P_{i j}}\right) /\left(\frac{\sum_{j} P_{i j}}{\sum_{i} \sum_{j} P_{i j}}\right)\right],
$$

where $P_{i j}$ is the number of patents of country $\mathrm{j}$ in patent category $\mathrm{i} ; \sum_{i} P_{i j}$ is the total number of patents owned by country $\mathrm{j} ;\left(P_{i j} / \sum_{i} P_{i j}\right)$ is the significance of patent category i to country $\mathrm{j} ; \sum_{j} P_{i j}$ is the total number of patents in the ith technical category; $\sum_{i} \sum_{j} P_{i j}$ is the total number of patents; $\left(\sum_{j} P_{i j} / \sum_{i} \sum_{j} P_{i j}\right)$ is the significance of the ith technical category to the industry's overall technology; and $\left[\left(P_{i j} / \sum_{i} \sum_{j} P_{i j}\right) /\left(\sum_{j} P_{i j} / \sum_{i} \sum_{j} P_{i j}\right)\right]$ is the relative significance of the ith patent category to country $j$ from the patent distribution in the entire industry. However, different technical categories may have widely varying significance in different countries, leading to extremely large or small values, and may thus impact position analysis. Therefore, In was used to process extreme values, while tanh was used to convert technical intensity into values ranging between 1 and -1 . The values obtained were then multiplied by 100 to make the RPA values fall between -100 and 100 . A positive RPA indicates a higher technical level, while a negative RPA represents lower technical level [14].

\section{K-means clustering analysis}

Once the RPA indexes were converted, SPSS K-means was used for clustering analysis for adjacent points in space. Strategic group were identified based on the similarity between data points. The core technological fields of the RFID industry in the countries in question were used as the grouping criteria. The countries were grouped depending on the intensity of technical fields to achieve a convergence of minimum difference within the group and maximum difference outside of group. The definitions of $[17,18]$ were then used to identify organizations with similar resources and strategies. Homogeneous data were then grouped together, and the grouping results were used to predict of the position of these countries in the various technological fields to ensure prediction accuracy [14].

\section{Research Results}

The present study assessed RFID industry development of China, Germany, Japan, Korea, the United States and Taiwan, their technical advantages and group position results from 1990 to 2010 . The potential of Taiwan's market was also investigated.

\section{Technical trends}

Data from the patent office of each of these countries was used to investigate technical trends and development status. The data was obtained from the Science \& Technology Policy Research and Information Center of the National Applied Research Laboratories, developed for long-term analysis of PATSTAT patents.

\section{Number of applications}

Figure 2 shows the cumulative number of patent applications in each of the RFID technical categories from 1990 to 2010. Concentrations are observed for $\mathrm{G} / 06 / \mathrm{F}$, $\mathrm{H} / 04 / \mathrm{M}$ and $\mathrm{G} / 06 / \mathrm{Q}$. G/06/F presents a particularly significant concentration with over 1,195,000 applications. Figure 3 shows that $\mathrm{G} / 06 / \mathrm{F}, \mathrm{H} / 04 / \mathrm{M}$ and $\mathrm{G} / 06 / \mathrm{Q}$ respectively accounted for $48.16 \%, 10.62 \%$ and $10.59 \%$ of the total applications. Figure 4 shows trend development for each category. For $G / 06 / F$, the number of applications grows continuously through 2005 and 
began to decline in 2009. The figures and tables clearly indicate that $\mathrm{G} / 06 / \mathrm{F}, \mathrm{H} / 04 / \mathrm{M}$ and $\mathrm{G} / 06 / \mathrm{Q}$ are preferred targets of RFID patent applications during this period.

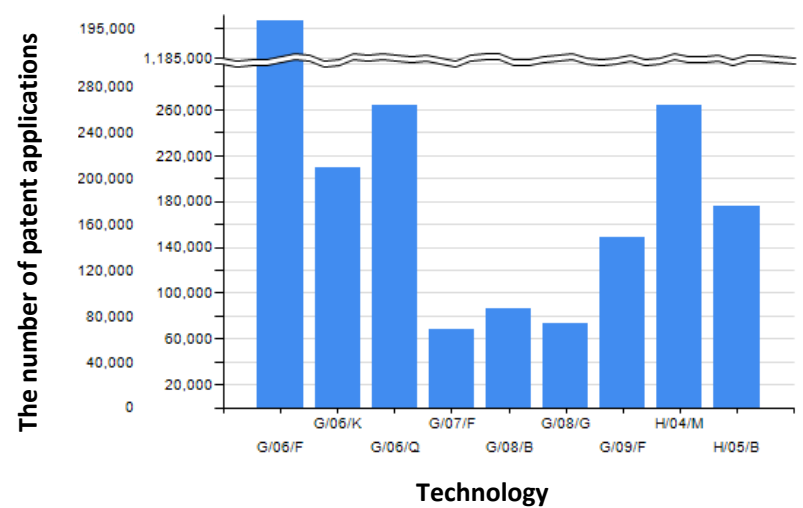

Figure 2. Cumulative number of patent applications for each technology from 1990 to 2010.
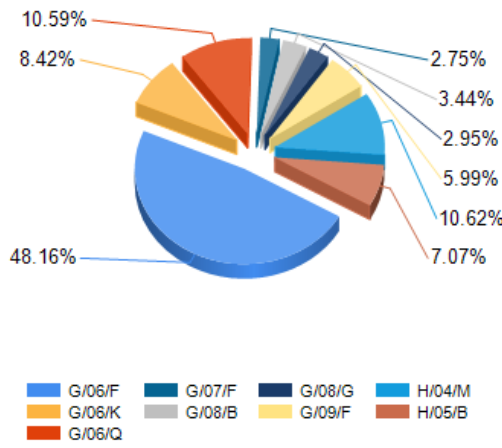

Figure 3. Distribution of of patent applications for each technology from 1990 to 2010

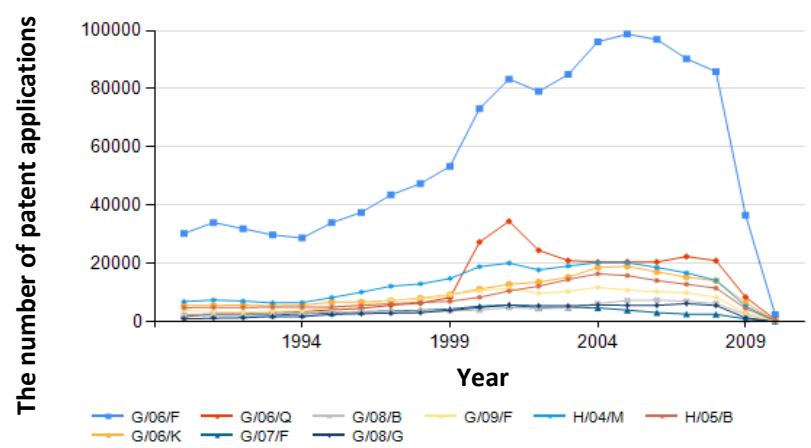

Figure 4. The trend chart of the number of patent applications of each technology from the 1990 to 2010.

\section{Number of PCTs}

Figure 5 shows the cumulative number of PCT patent applications in each RFID technological classification from 1990 to 2010. Concentrations are observed for $\mathrm{G} / 06 / \mathrm{F}, \mathrm{G} / 06 / \mathrm{K}$ and $\mathrm{H} / 04 / \mathrm{M}$, with $\mathrm{G} / 06 / \mathrm{F}$ accounting for more than 21,700 applications. $G / 06 / F$ is a valuable technology and countries therefore seek to protect their innovations in this area. Figure 6 shows that $\mathrm{G} / 06 / \mathrm{F}, \mathrm{G} / 06 / \mathrm{K}$ and $\mathrm{H} / 04 / \mathrm{M}$ respectively accounted for $41.68 \%, 13.93 \%$ and $12.40 \%$ of patent applications. $\mathrm{G} / 06 / \mathrm{K}$, while ranked 4 th in terms of number of applications, was ranked 2 nd in terms of the number of PCTs, possibly indicating it has a higher value than $\mathrm{G} / 06 / \mathrm{Q}$. Figure 7 shows that G/06/F consistently had the greatest number of PCT applications, exceeding 3,000 in 2009 , and it is clear that $\mathrm{G} / 06 / \mathrm{F}$ is the most valuable category. In terms of the number of PCTs, G/06/F and $\mathrm{H} / 04 / \mathrm{M}$ were more popular and valuable technical categories.

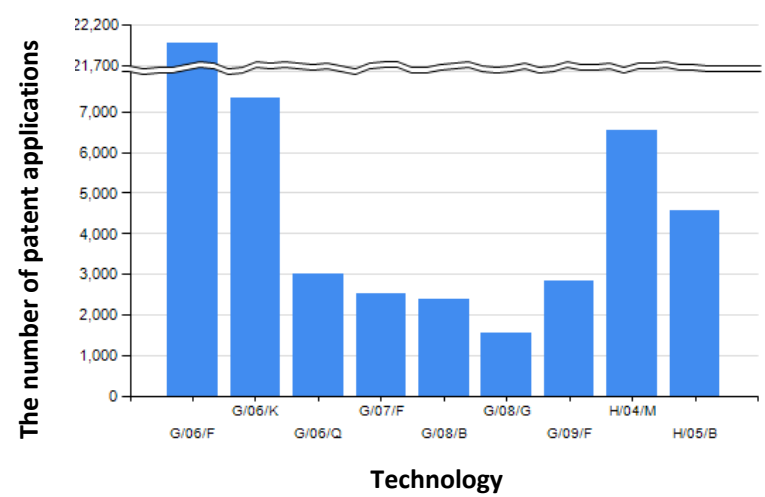

Figure 5. PCT cumulative number of patent applications for each technology from 1990 to 2010.
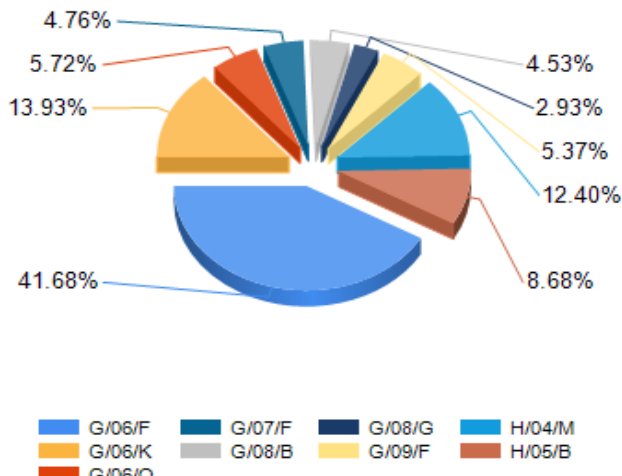

Figure 6. PCT distribution of patent applications for each technology from 1990 to 2010

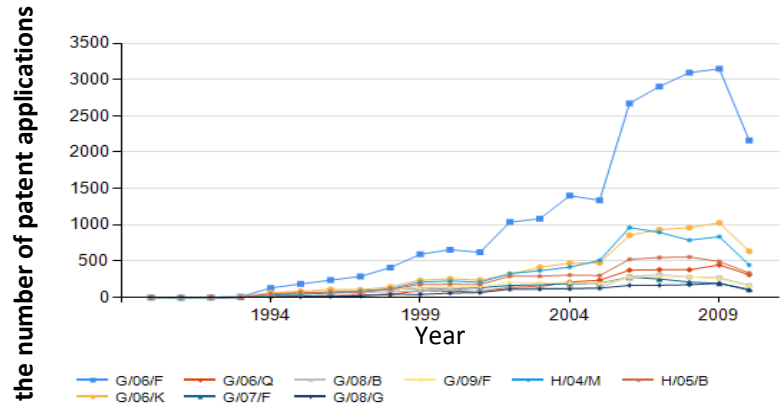

Figure 7. PCT patent application trends for each technology from 1990 to 2010 . 


\section{Countries and Technology}

The technical analysis in the previous section indicates that $\mathrm{G} / 06 / \mathrm{F}$ and $\mathrm{H} / 04 / \mathrm{M}$ were the most popular technologies during the period in question. In this section, these two technologies are examined using countries of application as the analysis objects. The numbers of applications and PCTs were used to investigate the relationship between countries and technology.

\section{Number of applications}

Figure 8 shows that Japan had the largest number of applications in G/06/F and H/04/M. From Fig. 8, we could infer that Japan has more resources in these two categories and uses these two technologies as its main development technologies. The United States and China have fewer applications than Japan.

The US RFID industry has grown rapidly since 2005 due to increased usage by Wal-Mart, leading to a strong increase in the number of related patent applications. China outpaced other countries in terms of the growth of applications due to long-term cooperation efforts with Germany and France combined with its own massive internal market.

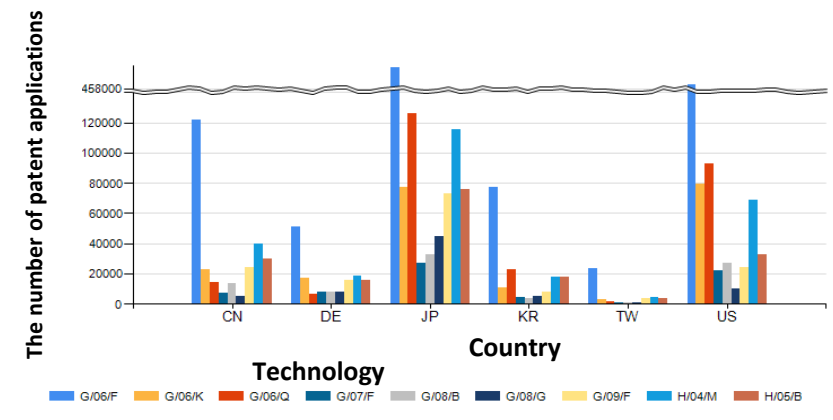

Figure 8. Technical patent applications for each technology by country from 1990 to 2010.

\section{Number of PCTs}

Figure 9 shows the different results for the number of applications. The United States has the highest number of PCT applications. The G/06/F and H/04/M categories were found to be more popular and valuable technological categories, implying that the US should apply for more PCTs to protect the value of these two technology categories in multiple countries.

DE and Japan JP ranked 2nd and 3rd behind US, suggesting that $\mathrm{G} / 06 / \mathrm{F}$ and $\mathrm{H} / 04 / \mathrm{M}$ are indispensable technologies for the development of a country's RFID industry, and that PCT applications protect value, thus allowing countries to improve their technological development capability. JP may outnumber US and DE in terms of absolute number of applications, but it does not enjoy the technical value secured by the US and Germany.

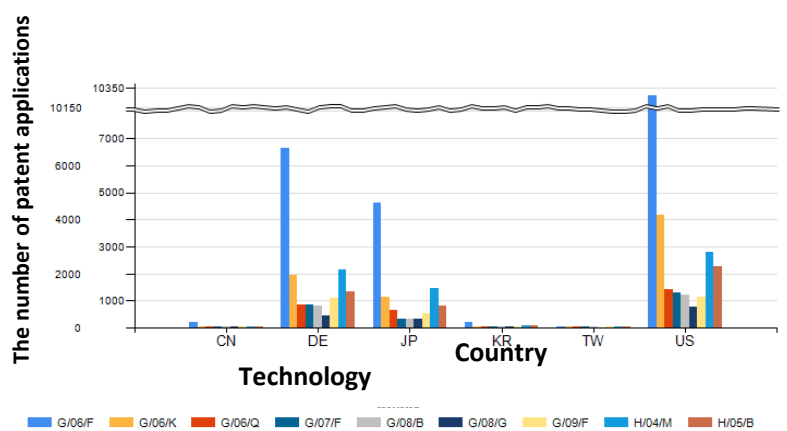

Figure 9. Technical patent applications for each technology by country from 1990 to 2010.

\section{Revealed Patent Advantage}

The Revealed Patent Advantage (RPA) indicates a country's relative technical advantage. The accumulated number of RFID patents of each country in Table 2 was converted into the RPA for a specific field shown in Table 3.

Table 3 shows that category with the highest technological level in these six countries is G/06/F. Specifically, the value of RPA indexes for both the US and Taiwan exceeded $90 \%$ for $G / 06 / F$, giving these two countries a strong relative advantage.

For US and TW, G/08/G had the lowest relative technical level at $-97.9 \%$ and $99.3 \%$, respectively, and the lowest technical level overall was for $G / 07 / F$, with a result of $-90 \%$ or less, except for DE $(-69 \%)$. Similar results were found for $\mathrm{G} / 08 / \mathrm{G}$ for all six countries.

Therefore, for these six countries, the technical level for these two categories was low and no relative advantage was to be had. KR enjoyed a relative advantage of approximately $9.7 \%$ for $\mathrm{G} / 06 / \mathrm{Q}$, while $\mathrm{DE}$ enjoyed a relative advantage of approximately $2.4 \%$ for $\mathrm{H} / 04 / \mathrm{M}$.

DE had the lowest technical level for $G / 06 / Q$ $(-78.8 \%)$, while $\mathrm{CN}$ had the lowest technical level for G/08/G (-95.6\%), JP had the lowest technical level for $\mathrm{G} / 07 / \mathrm{F}(-91.2 \%)$ and $\mathrm{KR}$ had the lowest technical level for G/08/B (-94.9\%). 
Table 2: RFID technical patent applications for each technology by country from 1990 to 2010 .

\begin{tabular}{lrrrrrrr} 
& \multicolumn{1}{c}{ CN } & \multicolumn{1}{c}{ DE } & \multicolumn{1}{c}{ JP } & \multicolumn{1}{c}{ KR } & \multicolumn{1}{c}{ TW } & US & \multicolumn{1}{c}{ Total } \\
G/06/F & 121,562 & 50,882 & 465,316 & 77,510 & 23,225 & 459,395 & $1,197,890$ \\
G/06/K & 22,565 & 16,855 & 76,980 & 10,628 & 3,062 & 79,395 & 209,485 \\
G/06/Q & 14,372 & 6,176 & 126,270 & 22,495 & 1,278 & 92,862 & 263,453 \\
G/07/F & 6,914 & 7,643 & 27,244 & 4,077 & 670 & 21,790 & 68,338 \\
G/08/B & 13,698 & 7,761 & 32,962 & 3,314 & 1,040 & 26,906 & 85,681 \\
G/08/G & 5,095 & 7,829 & 44,427 & 5,377 & 295 & 10,256 & 73,279 \\
G/09/F & 24,285 & 15,853 & 72,874 & 7,862 & 3,943 & 24,266 & 149,083 \\
H/04/M & 39,603 & 18,374 & 115,482 & 17,631 & 4,144 & 68,866 & 264,100 \\
H/05/B & 30,157 & 15,426 & 75,793 & 18,022 & 3,709 & 32,721 & 175,828 \\
Total & 278,251 & 146,799 & $1,037,348$ & 166,916 & 41,366 & 816,457 & $\mathbf{2 , 4 8 7 , 1 3 7}$ \\
\hline
\end{tabular}

Total RFID-related patent applications for the six countries: 2,487,137; Total patent applications of all industries for the six countries : $20,346,207$

Table 3: RPA value by RFID technology field for each country.

\begin{tabular}{lcccccc} 
& CN & DE & JP & KR & TW & US \\
G/06/F & 85.47873 & 77.87581 & 86.17376 & 87.03881 & 90.94842 & 90.98579 \\
G/06/K & -38.87794 & -6.25728 & -46.14207 & -57.31735 & -46.33971 & -22.48671 \\
G/06/Q & -69.70191 & -78.81886 & -0.42379 & 9.72562 & -87.99171 & -7.19728 \\
G/07/F & -92.06405 & -69.28996 & -91.17545 & -92.32142 & -96.54934 & -90.90040 \\
G/08/B & -72.08977 & -68.48496 & -87.34157 & -94.85958 & -91.88321 & -86.44935 \\
, G/08/G & -95.61090 & -68.01898 & -78.13444 & -87.01259 & -99.32161 & -97.91010 \\
G/09/F & -32.47092 & -12.33124 & -50.34587 & -74.14478 & -24.37481 & -88.83691 \\
H/04/M & -15.09803 & 2.36301 & -9.32738 & -14.50396 & -19.64482 & -35.49092 \\
H/05/B & -11.97666 & -15.01048 & -47.35638 & -12.35014 & -30.03777 & -80.58910 \\
\hline
\end{tabular}

\section{$K$-means clustering analysis}

SPSS K-means clustering analysis was used to group these countries and their technical data, to thus identify these countries' relative positions within the RFID industry and their relative development strength in these fields. The convergence of minimum difference within groups and maximum difference outside of groups was achieved with 4 groups. Therefore, the grouping of countries and technologies was investigated based on 4 groups, as shown in Tables 4 and 5.

In Table 4, Case Numbers 1 to 6 respectively represents $C N, D E, J P, K R, T W$ and US. Grouping countries by similar characteristics, the 1st group consisted of $\mathrm{CN}$ and TW, with a distance of 17.736 from the group center to these two countries. Germany was the center of the 2nd group, and the US was the center of the 3rd group. The 4th group was consisted of Japan and Korea, with a distance of 23.366 from the group center to these two countries.

In Table 5, Case Numbers 1 to 9 respectively represent G/06/F, G/06/K, G/06/Q, G/07/F, G/08/B, G/08/G, G/09/F, H/04/M and H/05/B. Grouping countries by technologies, the 1st group was $\mathrm{G} / 06 / \mathrm{F}$ and the 2 nd group was $\mathrm{G} / 06 / \mathrm{K}, \mathrm{G} / 09 / \mathrm{F}, \mathrm{H} / 04 / \mathrm{M}$ and $\mathrm{H} / 05 / \mathrm{B}$, both having a center distance of 39.980 , and respectively lying $45.022,49.782,47.193$ and 39.980 from the technical center. The 3rd group was $\mathrm{G} / 06 / \mathrm{Q}$ and the 4 th was $\mathrm{G} / 07 / \mathrm{F}, \mathrm{G} / 08 / \mathrm{B}$ and $\mathrm{G} / 08 / \mathrm{G}$, both with a center distance of 14.344 , and respectively lying $8.005,16.426$ and 14.344 from the technical center.

Tables 4 and 5 provide the following information: Group 1 (CN and TW) develops technology based on G/06/F, meaning that China and Taiwan focus on applications for digital electronic data processing in the RFID industry; Group 2 (DE) develops technologies based on $\mathrm{G} / 06 / \mathrm{K}, \mathrm{G} / 09 / \mathrm{F}, \mathrm{H} / 04 / \mathrm{M}$ and $\mathrm{H} / 05 / \mathrm{B}$, indicating that $D E$ focuses on the applications for data ID, advertisement marking, telecommunications technologies and electric lighting in the RFID industry; Group 3 (US) develops technologies based on $\mathrm{G} / 06 / \mathrm{Q}$, indicating that the US focuses on the data processing systems for administration and management in the RFID industry. Group 4 (JP and KR) develops technologies based on G/07/F, G/08/B and G/08/G, indicating that Japan and Korea focus on applications for signaling devices and traffic control systems in the RFID industry.

Table 4: k-means clustering - Country.

\begin{tabular}{cccc}
\hline \multicolumn{2}{c}{ Cluster Number } & Cluster & Distance \\
\hline 1 & CN & 1 & 17.736 \\
\hline 2 & DE & 2 & .000 \\
\hline 3 & JP & 4 & 23.366 \\
\hline 4 & KR & 4 & 23.366 \\
\hline 5 & TW & 1 & 17.736 \\
\hline 6 & US & 3 & .000
\end{tabular}

Table 5: k-means clustering - Technology.

\begin{tabular}{cccc}
\hline \multicolumn{2}{c}{ Cluster Number } & Cluster & Distance \\
\hline 1 & G/06/F & 1 & .000 \\
\hline 2 & G/06/K & 2 & 45.022 \\
\hline 3 & G/06/Q & 3 & .000 \\
\hline 4 & G/07/F & 4 & 8.005 \\
\hline 5 & G/08/B & 4 & 16.426 \\
\hline 6 & G/08/G & 4 & 14.334 \\
\hline 7 & G/09/F & 2 & 49.782 \\
\hline 8 & H/04/M & 2 & 47.193 \\
\hline 9 & H/05/B & 2 & 39.980
\end{tabular}

\section{Conclusion}

This study was examined RFID patents in China, Germany, Japan, Korea, Taiwan and the United States between 1990 and 2010. Patent indexes, specifically the number of applications and PCTs, were examined from 
the perspectives of "technical trends" and "country and technology," to assess the relative development of these countries to identify trends for the global RFID industry. RPA and K-means clustering analysis were used to identify the relative positions of these countries in the RFID industry, their development strengths in specific fields and their directions for future development, thus providing insight into Taiwan's market potential.

The following conclusion was achieved for "technical trends": (1) G/06/F and H/04/M are the widely applied and valuable technologies; (2) G/06/F may be a core technology for technical development, but the number of related patents has dropped substantially since 2009, indicating that the technology and should command fewer resources moving forward; (3) H/04/M is a valuable technology and is the subject of relatively more applications. However, as seen in Figs. 4 and 8, the number of patent applications for $\mathrm{H} / 04 / \mathrm{M}$ has dropped more slowly than for $G / 06 / F$ since 2009. Given the increasing maturity of this technology, it's possible that many countries have elected to focus on improving existing products, leading to a decline in patent applications in these two categories. Thus, we can infer that there is still space for development but room for growth is shrinking.

The following conclusion was drawn for "country and technology": (1) the number of applications or PCTs for both $G / 06 / F$ and $H / 04 / M$ outnumbered other categories in all six countries, therefore indicating that these two technology categories are the focuses of RFID development; (2) Japan the best RFID development of the Asian countries, while the United States started earlier in RFID development and thus has more applications. This suggests that Japan and the United States have superior technical resources in $\mathrm{G} / 06 / \mathrm{F}$ and $\mathrm{H} / \mathrm{O} 4 / \mathrm{M}$; (3) the number of PCTs suggests that the core of development in the United States are G/06/F and $\mathrm{H} / 04 / \mathrm{M}$, with Germany and Japan ranking 2nd and 3rd behind the US. In addition, Europe is the largest RFID market, giving rise to, many PCT applications in multiple countries to protect the value of their patented technologies.

Wu et al. [2] suggested that International Patent Classification could be used to identify the development directions of major competitors and future development opportunities in any industry. That conclusion is supported by our IPC patent analysis for the RFID industry. Our research indicates that that $G / 06 / B$ and $\mathrm{G} / 06 / \mathrm{K}$ are the two main technologies in the RFID development process, but analysis on patent applications and PTC (Patent Cooperation Treaties) indicates that the two most valuable technologies between 1990 and 2010 were $\mathrm{G} / 06 / \mathrm{F}$ and $\mathrm{H} / 04 / \mathrm{M}$.
Analysis of the number of patent applications and PCT patent applications provides insight into major trends in technology development and also allows us to explore valuable patent technologies in the RFID industry through the PCT process. Furthermore, we can precisely assess key technology developments in each country, along with research trends and applications. These results can only be achieved by analyzing both patent indicators.

RPA index and K-means clustering analysis show the relative technical positions of these countries in the RFID industry, and it is hoped that this can help Taiwan improve its position in the global RFID patent configuration. In particular, technical interaction and cooperation with other countries can effectively enhance Taiwan's technical capabilities, strengthening Taiwan's competitive advantage in terms of RFID technological development.

This study applies the number of patent applications and the number of PCT applications to explore valuable directions for the development of RFID technology. RPA indexes and K-means cluster analysis were used to explore the relative advantages of the technology development of different countries. The results provided insights into appropriate development directions for RFID technology in the various countries, which can serve as a reference for the formulation of patent portfolio strategies.

RPA index and K-means cluster analysis of and time trend analysis not only helps identify the most widely applied and valuable technologies, but also highlights the dominant and developing technologies for individual countries. The proposed approach is found to provide a more accurate analysis of the overall RFID industrial development of each country.

\section{Research Contribution}

The results of this research provide insight into current and future technology development trends, allowing for the appropriate adjustment of development strategies and for the effective protection of key technologies through patents. This research also helps identify technologies which are likely to have particular future value, allowing firms and governments to better apply resources to obtain maximum value while minimizing risks of losing control of valuable innovations. Applying these measures to particular technologies may help Taiwan establish a strong position in the RFID industry.

The results also can potentially help scholars better understand developments in the RFID industry. Future research can thus be better focused on technologies with greater potential value, and researchers will also be 
better able to identify international development partners with complementary relative advantages. In particular, the results suggest that Taiwan and the US should potentially cooperate in the development of $\mathrm{G} / 06 / \mathrm{F}$ technologies, and the value of such partnerships can be further explored in future research.

\section{Research Limitation}

The PATSTAT database features records on more than 80 million patents but, due to logistical and funding limitations, this study focused on the following areas:

Due to funding and logistical restrictions, not all IPC search results were reviewed. In addition, while the study attempts to compare conditions in six different countries, differences in national patent laws, reviewing mechanisms and process times can result in unique issues which are not explored in this study.

\section{References}

[1] Y. M. Hsu, "Brief discussion on the application of RFID in library," National Central University Library Newsletter, vol. 41, pp. 17-23, 2005 (In Chinese).

[2] Y. C. J. Wu and T. C. Yen, "RFID technology innovations: The use of patent data," International Journal of Manufacturing Technology and Management, vol. 10, no. 1, pp. 106-120, 2006. doi: 10.1504/IJMTM.2007.011404

[3] L. C. Hsu, "Brief discussion on the patent kingdoms: Donald duck and table tennis," Mototeru publication, 2010.

[4] D. R. Chen and M. S. Huang, Patent information-retrieval, analysis and strategies. Taiwan: Prentice Hall Business Corporation, 2009.

[5] Y. J. Wu and C. H. Lin, "Warehousing innovations: A patenting view," Operations Research Bulletin, vol. 7, pp. 47-58, 2005 (In Chinese).

[6] Y. H. Tseng, C. J. Lin, and Y. I. Lin, "Text mining techniques for patent analysis," Information Processing \& Management, vol. 43, no. 5, pp. 1216-1247, 2007.

doi: 10.1016/j.ipm.2006.11.011

[7] C. Y. Liu and J. C. Yang, "Decoding patent information using patent maps," Data Science Journal, vol. 7, pp. 14-22, 2008.

doi: $10.2481 /$ dsj.7.14

[8] Y. S. Chang, "Patent analysis of wind generation in u.S., europe and taiwan," Master, Graduate Institute of Technology Management, National Taiwan University of Science and Technology, Taiwan, 2011
[9] A. J. C. Trappey, C. V. Trappey, C. Y. Wu, C. Y. Fan, and Y. L. Lin, "Intelligent recommendation methodology and system for patent search," in the 16th International Conference on Computer Supported Cooperative Work in Design (CSCWD 2012) Wuhan, China, 2012, pp. 172-178. doi: 10.1109/CSCWD.2012.6221815

[10] A. J. C. Trappey and P. M. Wognum, "Special issue on RFID and sustainable value chains," Advanced Engineering Informatics, vol. 25, no. 1, pp. 2-3, 2011.

doi: 10.1016/i.aei.2010.06.005

[11] C. V. Trappey, H. Y. Wu, F. Taghaboni-Dutta, and A. J. C. Trappey, "Using patent data for technology forecasting: China rfid patent analysis," Advanced Engineering Informatics, vol. 25, no. 1, pp. 53-64, 2011.

doi: $10.1016 /$ j.aei.2010.05.007

[12] S. Govada, S. Kandekar, R. Pejaver, and J. Wahlman, "Patent analysis of RFID technology," MIS 580Knowledge Management Project, 2008.

[13] C. V. Trappey, H. Y. Wu, T. D. Fataneh, and A. J. C. Trappey, "China RFID patent analysis," Proceedings of the ASME 2009 International Manufacturing Science and Engineering Conference, vol. 1, pp. 237-245, 2009. doi: $10.1115 /$ MSEC2009-84168

[14] C. Y. Fan, M. F. Lai, T. Y. Huang, and C. M. Huang "Applying k-means clustering and technology map in asia pacific-semiconductors industry analysis," in IEEE International Conference on Industrial Engineering and Engineering Management (IEEM), , 2011, pp. 1043-1047. doi: $10.1109 /$ IEEM.2011.6118074

[15] M. S. Yuan, "The study of development of patent indexes," Journal of Library and Information Science, vol. 35, no. 2, pp. 88-106, 2009 (In Chinese).

[16] U. Schmoch, "Evaluation of technology strategies of companies by means of mds maps," International journal of technology Management, vol. 10, no. 4-5, pp. 426-440, 1995. doi: $10.1504 /$ IJTM.1995.025635

[17] M. E. Porter, Competitive strategy : Techniques for analyzing industries and competitors. New York: Free Press, 1980.

[18] K. J. Hatten and M. L. Hatten, "Strategic groups, asymmetrical mobility barriers and contestability," Strategic Management Journal, vol. 8, no. 4, pp. 329-342, 1987. doi: $10.1002 / \mathrm{smj} .4250080404$ 